\title{
Numerical modeling of bending, buckling, and vibration of functionally graded beams by using a higher-order shear deformation theory
}

\author{
Nabil Hebbar \\ Department of Civil Engineering and Architecture, University of Abdelhamid Ibn-Badis, Mostaganem, Algeria. \\ nabil_al@botmail.fr, bttps://orcid.org/0000-0001-7648-9875
}

Imène Hebbar

Department of Mechanical Engineering, University of Sidi Bel Abbes, Sidi Bel Abbes, Algeria. imhebbar@gmail.com

\section{Djamel Ouinas}

Department of Mechanical Engineering, University of Abdelhamid Ibn-Badis, Mostaganem, Algeria. douinas@netcourrier.com

Mohamed Bourada

Department of Civil Engineering, University of Sidi Bel Abbes, Sidi Bel Abbes, Algeria. Med_bourada@yahoo.fr

\begin{abstract}
The objective of this work is to analyze the behavior beams functionally graded, simply supported, under different conditions such as bending, buckling, and vibration and this by use shear deformation theories a two-dimensional (2D) and quasi-three-dimensional (quasi-3D). The proposed theories take into account a new field of displacement which includes indeterminate whole terms and contains fewer unknowns, compared to other theories of the literature; by taking account of the effects of the transverse shears and the thickness stretching. In this theory, the distribution of the transverse shear stress is hyperbolic and satisfies the boundary conditions on the upper and lower surfaces of the beam without the need for a shear correction factor. In this type of beam the properties of the materials vary according to a distribution of the volume fraction, the Hamilton principle is used to calculate the equations of motion, and in order to check the accuracy of the theory used comparison is made with the studies existing in the literature.
\end{abstract}

KEYwORDS. Functionally graded beams; Bending; Buckling; Vibration; Hyperbolic theory of shear deformation.

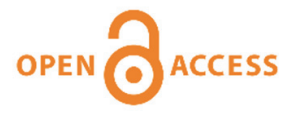

Citation: Hebbar, N., Hebbar, I., Ouinas, D., Bourada, M., Numerical modeling of bending, buckling, and vibration of functionally graded beams by using a higher-order shear deformation theory, Frattura ed Integrità Strutturale, 52 (2020) 230-246.

Received: 12.02 .2020

Accepted: 16.02 .2020

Published: 01.04.2020

Copyright: (C) 2020 This is an open access article under the terms of the CC-BY 4.0, which permits unrestricted use, distribution, and reproduction in any medium, provided the original author and source are credited. 


\section{INTRODUCTION}

$\mathrm{I}$ $\mathrm{n}$ recent decades, a new class of composite materials has emerged from a group of researchers at the National Aerospace Laboratory (STA) in Japan, where they have developed a functionally graded materials with characteristics to withstand with thermal and mechanical stresses[1], since the classic materials, despite their advantages of high rigidity, high and low mechanical resistance, do not always meet the required requirements, these functionally graded materials have a microstructure that varies gradually and constantly through the thickness in order to optimize their performances whether mechanical or thermal or both at the same time. Fig.1 shows the microstructure of functionally graded materials [2].

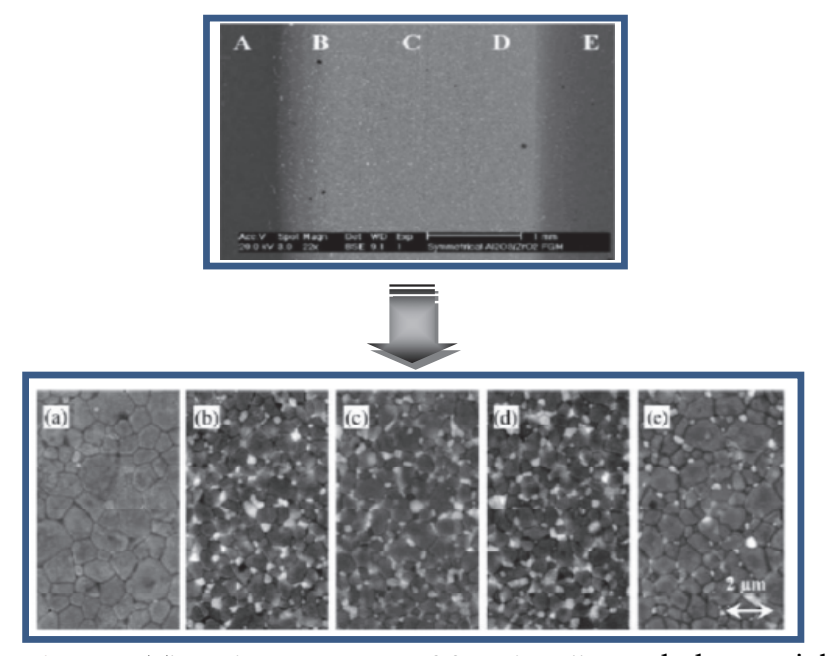

Figure 1: The microstructure of functionally graded materials.

Today, structures in advanced composite materials attract several researchers who are immersed in this vast field of research where they have developed several models in order to study the behavior of beams, plates and shells in different applications such as Koizumi [3-5], Karama et al.[6] and Aydogdu et al. [7] where they used a first-order parabolic and the exponential deformation theory to study the free vibration behavior of a functionally graded and simply supported material beam. Bernoulli [8] and Euler [9] have developed a classical theory (CBT) for the analysis of isotropic and anisotropic beams but unfortunately, this theory does not take into account the effect of transverse shear deformation. In order to overcome these limitations, several researchers have introduced the theory of shear deformation which takes into account the effect of transverse shear for the first-order theory and higher-order (HSDT). Timoshenko [10] introduced in his first-order theory the effect of shear deformation but always remains that he must add a correction factor and this is due to the shear stress that is constant across the thickness. These difficulties are eliminated by the introduction of the theory of higher-order shear deformation by researchers Reddy [11] and Touratier [12] they proposed work in bending, buckling and free vibration. Matsunaga [13] investigated the buckling and free vibration of FGM plates using a twodimensional deformation theory. Vidal et al.[14] carried out an evaluation of the sine model for nonlinear analysis of composite beams. Şimşek [15] used the different higher-order theories to study the dynamic responses of beams in functionally graded materials. Talha et al.[16] studied the static and dynamic response of FGM plates using the theory of higher-order shear strain. Hosseini-Hashemi et al. [17] investigated the free vibration of rectangular-type FGM plates using the first-order shear deformation theory. Hosseini-Hashemi et al. [18] proposed a new analytical approach to study the free vibration of rectangular Reissner-Mindlin plates. Xiang et al. [19] provided a theory of $\mathrm{n}$-shear deformation for the purpose of studying the free vibration of sandwich plates. Thai and Vo [20] have worked on the analysis of the buckling and vibration of beams in functionally graded materials by using higher-order shear deformation theory for beams. Reddy et al. [21] proposed a theory of torque stress depended on the microstructure of functionally graded beams. Eltaher et al. [22] determined the position of the neutral axis and its effect on the eigenfrequencies of functionally graded macros/nano-beams. Li and Batra [23] proposed a relational analysis between the critical buckling loads of a Timoshenko theory of beams and Euler-Bernoulli for different boundary conditions. Nguyen et al. [24] used the theory of first-order shear deformation to analyze the vibration of beams in graded functional materials to obtain an analytical solution 
according to Navier's solution. Hadji et al. [25] have developed a new model of first-order and higher-order shear deformation to analyze the vibration of functionally graded beams. Yaghoobi et al. [26] developed an analytical study on the analysis of nonlinear free vibrations after beam buckling in functionally graded materials resting on a non-linear elastic foundation under thermo mechanical loading using VIM. Rahmani and Pedram [27] they analyzed by modeling the effect of size on the vibration of functionally graded nano-beams based on the nonlocal Timoshenko beam theory. AlKhateeb and Zenkour [28] presented a refined four-variable theory for the analysis of flexion of resting plates on elastic foundations in hygrothermal environments. Vo et al. [29, 30] developed a finite element model based on a refined theory of shear deformation in order to study the static and dynamic behavior of beams under different boundary conditions. Meradjah et al. [31] proposed a new theory of shear deformation for the study of beams in functionally graded materials with a consideration of the stretching effect. Vo et al. [32] developed a quasi-3D theory for the study of buckling and vibration of sandwich beams. Zemri, A et al. [33] proposed an unrefined theory of theory for static analysis, buckling and free vibration of beams in nanometrically functionally graded materials. Al-Basyouni et al. [34] analyzed flexion and vibration as a function of the size of functionally graded micro-beams based on the modified theory of torque stress and neutral surface position. Ebrahimi and Dashti [35] explored the effects of linear and non-linear distributions of temperature on the vibration of nano-beams in functionally graded materials. Kar and Panda [36] studied the vibration and nonlinear shear bending of a spherical shaped, shell panel is functionally graded materials. Bourada et al. [37] presented a new simple and refined higher-order trigonometric theory for the analysis of free bending and vibration of beams in functionally graded materials taking into account the effect of stretching the thickness. Celebi et al. [38] proposed a unified method for studying the constraints in a sphere of functionally graded materials with properties that vary exponentially. Boukhari et al. [39] proposed a thermal study on wave propagation in FGM functionally graded materials plates based on the neutral surface position. Ebrahimi and Barati [40] have studied the influence of the environment on the damping vibration of nano-beams in functionally graded materials. Ahouel et al. [41] investigated the size-dependent mechanical behavior of trigonometrically shear functional and trigonometric shear nano-beams, including the concept of the neutral surface position. Shafiei et al. [42] studied the nonlinear vibrations of conical micro-beams in functionally graded imperfect and porous materials based on modified torque constraints and Euler-Bernoulli theories. Raminnea et al. [43] used the non-linear Reddy theory of higher-order for the study of the vibration and instability of embedded pipes carrying a fluid as a function of temperature. Ghumare and Sayyad [44] developed a new theory for the study of fifth-order shear deformation and normal deformation for the analysis of flexion and free vibration of FGM beams. Benadouda et al. [45] proposed a theory of shear deformation for the study of wave propagation in beams in functionally graded materials with porosities. Bellifa et al. [46] used a theory of simple shear deformation as well as the concept of the position of the neutral surface for the analysis of flexion and free vibration of plates made of functionally graded materials. Akbaş $[47,48]$ studied the vibratory response of viscoelastic beams and wave propagation in a beam made of functionally graded materials in thermal environments. Bellifa et al. [49] used the theory of non-local zero-order shear strain for the non-linear post-buckling of nano-beams. Li et al. [50] studied the effect of thickness on the mechanical behavior of nano-beams. Sayyad and Ghugal [51] developed a theory of unified shear deformation for the study of the bending of beams and plates in functionally graded materials. Aldousari [52] studied the bending analysis of different material distributions in a functionally graded beam. Bouafia et al. [53] developed a non-local quasi-3D theory to study the behavior of the free bending of nano-beams in functionally graded materials. Zidi et al. [54] have proposed a new simple two-unknown theory for studying the hyperbolic shear deformation of beams in functionally graded materials. Fouda et al. [55] proposed a porosity model to study shear deformation in the static case, buckling and free vibration of porous beams in functionally graded materials based on the Euler Bernoulli method and finite elements. A study on the free vibration of beams in functionally graded materials is presented by Zaoui et al. [56] where they used a theory of higher-order shear deformation. Mouffoki et al. [57] studied the analysis of the free vibration of nano-beams under a hygro-thermal loading using a new theory of trigonometric beams with two unknowns. Recently, Sayyad and Ghugal [58] studied the bending, buckling and free vibration responses of the hyperbolic shear deformation of FGM beams. Kaci. A. et al. [59] have studied the post-buckling analysis of shear-deformable composite beams using a new, simple two-unknown theory. Dragan et al. [60] developed a new function for the purpose of analyzing plate bending in functionally graded materials. The effect of shear deformation of structures in functionally graded materials requires more investigation. In our study, a theory of $2 \mathrm{D}$ and quasi-3D three-variable shear deformation for the analysis of beams in functionally graded materials is presented. The motion equations are derived from the Hamilton principle. Navier's solutions are also presented. Displacements, stresses, critical buckling loads and frequencies obtained using the current beam theory of functionally graded materials in which the properties of materials vary with the power-law (P-FGM) are compared with other results in order to demonstrate the effectiveness of the proposed theory. Numerical examples will be presented for the study of the shear deformation of beams in functionally graded materials in the case of bending, buckling and vibration. 


\section{MATHEMATICAL MODELING}

\section{Formulation of the problem}

onsider a beam of functionally graded materials of uniform length (a) width (b) and thickness (h), it is represented in the Fig.2. The Cartesian coordinate system $\mathrm{x}, \mathrm{y}, \mathrm{z}$ at $\mathrm{z}=0$ the plane $\mathrm{x}, \mathrm{y}$ coincides with the median surface of the beam.

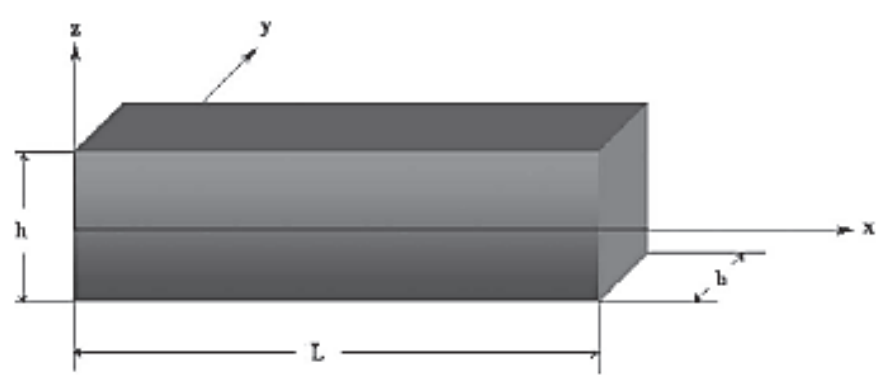

Figure 2: The geometry of functionally graded beam.

The characteristics of the material can change according to the thickness and the function given in the following equations $[24,57,61,62,63]:$

$$
\begin{aligned}
& E(z)=E_{m}+\left(E_{c}-E_{m}\right)[(1 / 2)+(z / h)]^{p} \\
& \rho(z)=\rho_{m}+\left(\rho_{c}-\rho_{m}\right)[(1 / 2)+(z / h)]^{p} \\
& G(z)=G_{m}+\left(G_{c}-G_{m}\right)[(1 / 2)+(z / b)]^{p}
\end{aligned}
$$

where: Ec and Em present the property of the upper and lower faces of the beam respectively and $\mathrm{p}$ is the exponent which specifies the distribution profile of the material in the thickness. In this work, Young's modulus $\mathrm{E}$ and the shear modulus G, change according to the problem case according to Eqn. (1), and the Poisson's ratio $v$ is considered constant.

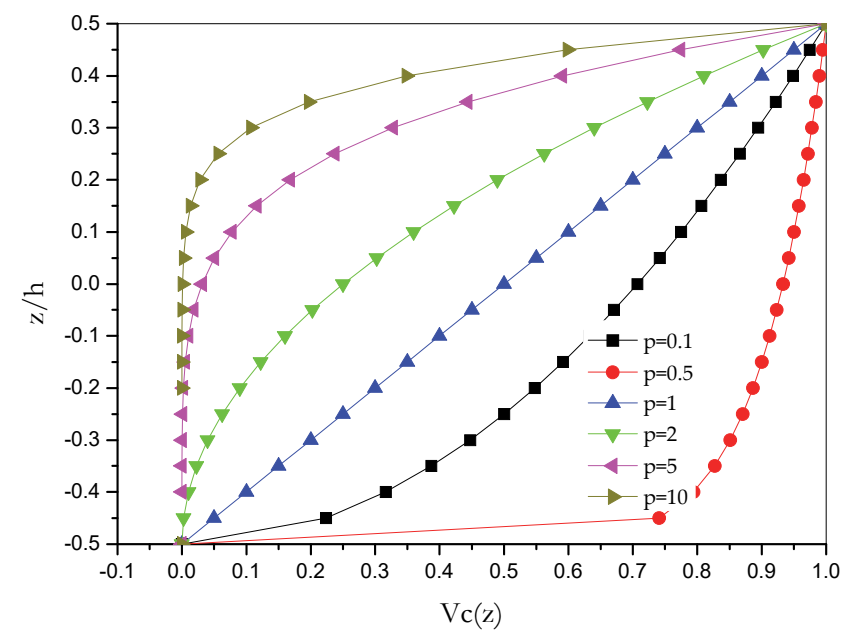

Figure 3: Variation of the volume fraction Vc across the thickness of a beam in FG for different values of the index of the power-law. 


\section{BASIC ASSUMPTIONS}

he hypotheses of the present theory are as follows; the origin of the Cartesian coordinate system is taken on the neutral axis of the beam in functionally graded materials;

The displacements are small in comparison with the thickness of the beam thus the deformations involved are infinitesimal;

Displacements $(\mathbf{u})$ in the $\mathrm{x}$ direction consist of extension, bending and shear components.

\section{KINEMATIC AND CONSTITUTIVE EQUATION}

$\mathrm{O}$

$\mathrm{n}$ the basis of the assumptions made in the previous section, the displacement field can be presented as follows:

$$
\begin{aligned}
& u(x, z, t)=u_{0}(x, t)-z \frac{\partial w_{0}(x, t)}{\partial x}+K_{a} f(z) \int \theta(x, t) d x, \\
& v(x, z, t)=0, \\
& w(x, z, t)=w_{0}(x, t)+g(z) \theta(x, t),
\end{aligned}
$$

where: $u_{0}$ is the axial displacement in the median plane, and t represents the time.

In this study, $\mathrm{f}(\mathrm{z})$ represents the shape function determining the distribution of transverse shear deformation as follows:

$$
f(z)=\frac{2 z \pi}{h}\left(\frac{z^{2}}{3}-\frac{h}{4}\right), g(z)=\frac{\partial f(z)}{\partial z}
$$

The deformations associated with displacements in Eqn. (4) are:

$$
\varepsilon_{x}=\varepsilon_{x}{ }^{0}+z k_{x}+f(z) \eta_{x}, \quad \gamma_{x z}=\frac{\partial f(z)}{\partial z} \gamma_{x z}^{0}
$$

where:

$$
\varepsilon_{x}{ }^{0}=\frac{\partial u_{0}}{\partial x}, k_{x}=-\frac{\partial^{2} w_{0}}{\partial x^{2}}, \eta_{x}=K_{a} A^{\prime} \theta, \gamma_{x z}^{0}=K_{a} \int \theta(x, t) d x
$$

and

$$
\varepsilon_{z}=g^{\prime}(z) \varepsilon_{z}^{0}, \varepsilon_{z}^{0}=\theta, g^{\prime}(z)=\frac{\partial g(z)}{\partial z}
$$

The Navier method is used to solve the integrals defined in the equations [64]:

$$
\int \theta d x=\mathrm{A}^{\prime} \frac{\partial \theta}{\partial x}
$$

where the coefficient $\mathrm{A}^{\prime}$ is considered according to the type of solution used, in this case via the Navier method. Consequently, $\mathrm{A}^{\prime}$ and $K_{a}$ are expressed as follows:

$$
\mathrm{A}^{\prime}=-\frac{1}{\alpha^{2}}, K_{a}=\alpha^{2}
$$

The beam in functionally graded materials obeys Hooke's law, so the behavioral relations can be given as follows: 


$$
\left\{\begin{array}{l}
\sigma_{x} \\
\sigma_{z} \\
\tau_{x z}
\end{array}\right\}=\left[\begin{array}{ccc}
Q_{11}(z) & Q_{13}(z) & 0 \\
Q_{13}(z) & Q_{33}(z) & 0 \\
0 & 0 & Q_{55}(z)
\end{array}\right]\left\{\begin{array}{l}
\varepsilon_{x} \\
\varepsilon_{z} \\
\gamma_{x z}
\end{array}\right\}
$$

with $\left(\sigma_{\mathrm{x}}, \sigma_{z}, \tau_{\mathrm{xz}}\right)$ and $\left(\varepsilon_{x}, \varepsilon_{z}, \gamma_{x z}\right)$ are respectively the stresses and the deformations.

The expressions $Q_{i j}$ depends on the normal deformation $\varepsilon_{z}:$

In the case of two-dimensional shear deformation (2D) the normal deformation $\varepsilon_{z}=0$, therefore:

$$
Q_{11}(z)=E(z) \text { and } Q_{55}(z)=\frac{E(z)}{2(1+v)}
$$

In the case of quasi-three-dimensional shear deformation (quasi-3D) the normal deformation $\varepsilon_{z} \neq 0$, therefore:

$$
Q_{11}(z)=Q_{33}(z)=\frac{E(z)}{1-v^{2}}, Q_{13}(z)=v Q_{11}(z) \text { and } Q_{55}(z)=\frac{E(z)}{2(1+v)}
$$

\section{EQUATION OF MOTION}

he Hamilton principle is used in this study to derive the equations of motion; it can be given in the following analytic form [65]:

$$
\int_{0}^{T} \delta(U+V-K) d t=0
$$

where: $\delta \mathrm{U}$ is the variation of the strain energy, $\delta \mathrm{V}$ is the variation of the kinetic energy and $\delta \mathrm{K}$ is the variation of the potential energy.

The variation of the deformation energy of the beam can be defined as follows:

$$
\begin{aligned}
& \delta U=\int_{0}^{L} \int_{-b / 2}^{b / 2} \int_{-b / 2}^{b / 2}\left(\sigma_{x} \delta \varepsilon_{x}+\tau_{x z} \delta \gamma_{x z}\right) d z d y d x \\
& \delta U=\int_{0}^{L}\left(N_{x} \frac{d \delta u_{0}}{d x}+M_{z} \delta \theta-M_{b} \frac{d^{2} \delta w_{0}}{d x^{2}}+M_{s} \frac{d \delta \theta}{d x}+Q \delta \theta\right) d x
\end{aligned}
$$

with:

$\mathrm{N}_{\mathrm{x}}, \mathrm{M}_{\mathrm{b}}, \mathrm{M}_{\mathrm{s}}$ and $\mathrm{Q}$ are the resultants of the stress in terms of axial force, bending moment, higher-order moment and shear force, respectively:

$$
\left(N_{x}, M_{b}, M_{s}\right)=\int_{-b / 2}^{b / 2}(1, z, f(z)) \sigma_{x} d z
$$




$$
\begin{aligned}
& {\left[\begin{array}{l}
N_{x} \\
M_{b} \\
M_{s}
\end{array}\right]=\int_{-b / 2}^{b / 2} \sigma_{x}\left[\begin{array}{c}
1 \\
z \\
f(z)
\end{array}\right] d z=\left[\begin{array}{l}
A_{11} \frac{d u_{0}}{d x}-B_{11} \frac{d^{2} w_{0}}{d x^{2}}+B_{11}^{s} \frac{d \phi}{d x} \\
B_{11} \frac{d u_{0}}{d x}-D_{11} \frac{d^{2} w_{0}}{d x^{2}}+D_{11}^{s} \frac{d \phi}{d x} \\
B_{11}^{s} \frac{d u_{0}}{d x}-D_{11}^{s} \frac{d^{2} w_{0}}{d x^{2}}+H_{11}^{s} \frac{d \phi}{d x}
\end{array}\right]} \\
& N_{z}=\int_{-b / 2}^{b / 2} \sigma_{z} g^{\prime}(z) d z, Q_{x z}=b \int_{-b / 2}^{b / 2} \tau_{x z} g(z) d z
\end{aligned}
$$

The variation of the kinetic energy is expressed by:

$$
\delta V=-\int_{0}^{L} q \delta w d x
$$

Furthermore, the potential energy of the distributed load is expressed by:

$$
\delta K=\int_{0}^{L} \int_{-b / 2}^{b / 2}[\dot{u} \delta \dot{u}+\dot{w} \delta \dot{w}] \rho(z) d z d x
$$

Substitute the expressions displacement by deformation as well as stress by deformation which are respectively defined by the Eqns. (16), (18) and (19) in Eqn. (14) and by integrating by parts while putting the coefficients $\delta \mathrm{u}, \delta \mathrm{v}, \delta \mathrm{w}$ and $\delta \theta$ equal to zero. As a result, the governing equations obtained are given as follows:

$$
\begin{aligned}
& \delta u_{0}: \quad \frac{\partial N_{x}}{\partial x}=I_{0} \ddot{u}_{0}-I_{1} \frac{\partial \ddot{w}_{0}}{\partial x}+J_{1} \frac{\partial \ddot{\varphi}}{\partial x} \\
& \delta w_{0}: \frac{\partial^{2} M_{b}}{\partial x^{2}}+q=N_{0}\left(\frac{\partial^{2} \ddot{u}_{0}}{\partial x^{2}}\right)+I_{0} \ddot{w}_{0}+I_{1}\left(\frac{\partial \ddot{u}_{0}}{\partial x}\right)+J_{2}\left(\frac{\partial \ddot{\varphi}}{\partial x}\right)-I_{2} \frac{\partial^{2} \ddot{w}_{0}}{\partial x^{2}} \\
& \delta \varphi: K_{a} \mathrm{~A}^{\prime} \frac{\partial M_{s}}{\partial x}-\frac{\partial Q_{x z}}{\partial x}-N_{z}=K_{a}^{2} J_{1} \ddot{u}_{0}+K_{a} J_{2} \frac{\partial \ddot{w}_{0}}{\partial x}-K_{2} \ddot{\varphi}
\end{aligned}
$$

with:

$$
\begin{aligned}
& A_{11}=b \int_{-b / 2}^{b / 2} Q_{11}(z) d z, B_{11}=b \int_{-b / 2}^{b / 2} Q_{11}(z) z d z, \\
& D_{11}=b \int_{-b / 2}^{b / 2} Q_{11}(z) z^{2} d z, B_{11}^{s}=b \int_{-b / 2}^{b / 2} Q_{11}(z) f(z) d z, \\
& D_{11}^{s}=b \int_{-b / 2}^{b / 2} Q_{11}(z) z f(z) d z, H^{s}=b \int_{-b / 2}^{b / 2} Q_{11}(z)[f(z)]^{2} d z, \\
& A_{55}^{s}=b \int_{-b / 2}^{b / 2} Q_{55}(z)[g(z)]^{2} d z
\end{aligned}
$$


where: $(\mathrm{z})$ is the density and $\mathrm{I}_{0}, \mathrm{I}_{1}, \mathrm{~J}_{1}, \mathrm{I}_{2}, \mathrm{~J}_{2}$ and $\mathrm{K}_{2}$ are the coefficients of inertia as defined below:

$$
\begin{aligned}
& I_{0}=b \int_{-b / 2}^{b / 2} \rho(z) d z, I_{1}=b \int_{-b / 2}^{b / 2} z \rho(z) d z, J_{1}=b \int_{-b / 2}^{b / 2} f(z) \rho(z) d z, \\
& I_{2}=b \int_{-b / 2}^{b / 2} z^{2} \rho(z) d z, J_{2}=b \int_{-b / 2}^{b / 2} z f(z) \rho(z) d z, K_{2}=b \int_{-b / 2}^{b / 2} f(z)^{2} \rho(z) d z
\end{aligned}
$$

\section{ANALYTICAL SOLUTION}

$\mathrm{T}$

he motion equations admit Navier's solutions for simply supported beams. The variables $\mathbf{u} 0$, wo and $\phi$ can be written assuming the following variations:

$$
\left[\begin{array}{l}
u_{0} \\
w_{0} \\
\phi
\end{array}\right]=\sum_{m=1,3,5}^{\infty}\left[\begin{array}{l}
u_{m} \cos \alpha x e^{i \omega t} \\
w_{m} \sin \alpha x e^{i \omega t} \\
\phi_{m} \cos \alpha x e^{i \omega t}
\end{array}\right]
$$

with: $\quad \mathrm{i}=\sqrt{-1}$ and $\alpha=\mathrm{m} \pi / \mathrm{L}$

The transverse load $\mathrm{q}$ is also expressed by the double series of Fourier sine as follows:

$$
q=\sum_{m=1,3,5}^{\infty} \frac{4 q_{0}}{m \pi} \sin \alpha x
$$

Substitute the expressions $\mathbf{u}_{0}, \mathrm{w}_{0}$ and $\phi$ of Eqn. (23) in the equation of motion (20). The analytical solution is given in the following form:

$$
\left(\left[\begin{array}{lll}
s_{11} & s_{12} & s_{13} \\
s_{12} & s_{22} & s_{23} \\
s_{13} & s_{23} & s_{33}
\end{array}\right]-\omega^{2}\left[\left[\begin{array}{lll}
m_{11} & m_{12} & m_{13} \\
m_{12} & m_{22} & m_{23} \\
m_{13} & m_{23} & m_{33}
\end{array}\right]\right)\left\{\begin{array}{l}
u_{m} \\
w_{m} \\
\phi_{m}
\end{array}\right\}=\left\{\begin{array}{c}
0 \\
\frac{4 q_{0}}{m \pi} \\
0
\end{array}\right\}\right.
$$

In which:

$\mathrm{S}_{11}=\mathrm{A}_{11} \alpha^{2}, \mathrm{~S}_{12}=-\mathrm{B}_{11} \alpha^{3}, \mathrm{~S}_{13}=K_{a} \mathrm{~A}^{\prime} \mathrm{D}_{11} \alpha^{2}, \mathrm{~S}_{22}=K_{a} \mathrm{~B}_{11}^{\mathrm{s}_{11}} \alpha^{2}, \mathrm{~S}_{23}=-K_{a} \mathrm{~A}^{\prime} \mathrm{D}^{\mathrm{s}_{11}} \alpha^{2}, \mathrm{~S}_{33}=K_{a}^{2} \mathrm{~A}^{\prime 2} \mathrm{H}_{11}^{\mathrm{s}_{11}} \alpha^{2}+K_{a}^{2} \mathrm{~A}^{\prime} \mathrm{A}_{55}^{\mathrm{s}}$

$\mathrm{m}_{11}=\mathrm{I}_{0}, \mathrm{~m}_{12}=-\mathrm{I}_{1} \alpha, \mathrm{m}_{13}=K_{a} \mathrm{~A}^{\prime} \mathrm{J}_{1} \alpha^{2}, \mathrm{~m}_{22}=\mathrm{I}_{2} \alpha^{2}+\mathrm{I}_{0}, \mathrm{~m}_{23}=-\mathrm{J}_{2} \alpha^{2}, \mathrm{~m}_{33}=K_{a}^{2} \mathrm{~A}^{\prime 2} \mathrm{~K}_{2} \alpha^{2}$

\section{NUMERICAL RESULTS AND DISCUSSION}

$\mathrm{I}$

$\mathrm{n}$ this section, various numerical examples are presented to verify the accuracy of the theory presented for the purpose of predicting bending, buckling, and vibration responses of a simply supported FG beam.

The properties of the materials change through the thickness of the beam according to a power-law. The lower surface of the beam is rich in aluminum and the upper surface of the beam is rich in alumina.

For convenience, the following dimensionless form is used:

$$
\bar{u}\left(0,0,-\frac{h}{2}\right)=\frac{w 100 E_{m} h^{3}}{q_{0} L^{4}}, \bar{w}\left(\frac{L}{2}, 0,0\right)=\frac{w 100 E_{m} h^{3}}{q_{0} L^{4}}, \bar{\sigma}_{x}\left(\frac{L}{2}, 0, \frac{h}{2}\right)=\frac{\sigma_{x} h}{q_{0} L}, \bar{\tau}_{x z}(0,0,0)=\frac{\tau_{x} h}{q_{0} L}, \varpi=\frac{\omega L^{2}}{h} \sqrt{\frac{P_{m}}{E_{m}}}, \bar{N}_{c r}=\frac{12 N_{0} a^{2}}{E_{m} h^{3}}
$$




\begin{tabular}{cccc}
\hline Material & Properties & \\
& Young's modulus $(\mathrm{GPa})$ & Poisson's ratio & Mass density $(\mathrm{kg} / \mathrm{m} 3)$ \\
Aluminum $(\mathrm{Al})$ & 70 & 0.3 & 2702 \\
Alumina $\left(\mathrm{AL}_{2} \mathrm{O}_{3}\right)$ & 380 & & 3960 \\
\hline
\end{tabular}

Table 1: Materials properties used in the FG beams.

\section{BENDING ANALYSIS}

$\mathrm{T}$ ab. 2 presents a comparison of dimensionless displacements and stresses of $\mathrm{Al} / \mathrm{Al}_{2} \mathrm{O}_{3}$ functionally graded materials beams, simply supported and subjected to uniformly distributed loads with different exponent values of the power-law $\mathrm{p}$ and for ratios. $\mathrm{L} / \mathrm{h}=5$ and 20 . It can be seen through the results obtained that displacements and stresses increase as the power-law index increases and takes a maximum value when $\mathrm{p}$ takes the value of one and a minimum value in the case where $\mathrm{p}$ takes the value of zero, this interpretation is due to the ductility of the beam since the more the material index is increasing, the more the beam becomes more ductile. The results obtained are compared with other results from the literature such as HSDT of Reddy [11], HSDT of Hadji et al. [25], and HSDT of A.S. Sayyad and Y.M. Ghugal [58]. It can also be noted that the two-dimensional (2D) shear deformation theory is in good agreement with the other theories of shear deformation, whereas the results obtained by the theory of quasi-shear deformation threedimensional (quasi-3D) are slightly larger compared to that of the literature and this is due to the effect of normal transversal deformation which is not neglected $\left(\varepsilon_{\mathrm{z}} \neq 0\right)$ compared to other theories where the effect normal transversal deformation is neglected $\left(\varepsilon_{\mathrm{z}}=0\right)$.

Fig. 4 shows the variation of the transverse displacement across the length of the beam made of $\mathrm{Al} / \mathrm{Al}_{2} \mathrm{O}_{3}$ functionally graded materials, subjected to a uniformly distributed load. It is noted that the transverse displacement increases with the increase of the index of the power-law $\mathrm{p}$ and reaches a maximum value. The traced curve takes a parabolic form.

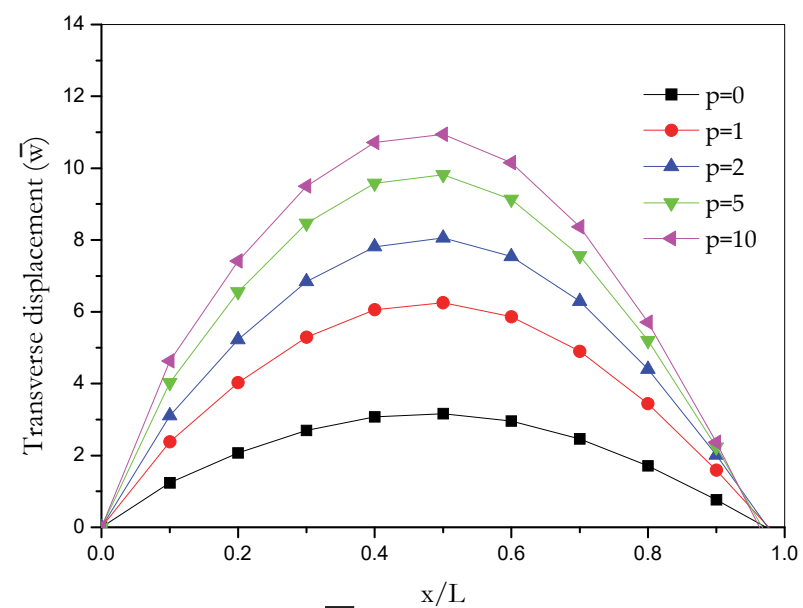

Figure 4: Variation of dimensionless transverse displacement $(\bar{w})$ along the length of the beam subjected to uniformly distributed load with a ratio $(\mathrm{L} / \mathrm{h}=5)$.

Fig. 5 shows the variation of the axial displacement across the length of the beam in $\mathrm{Al} / \mathrm{Al}_{2} \mathrm{O}_{3}$ functionally graded materials, subjected to a uniformly distributed load, for different values of the index of the power-law $p$. It can be seen that the axial displacement is maximum when the index of the power-law takes the value of one and it is minimal in the case where the index of the power-law takes the value of zero.

Fig. 6 shows the variation of the axial displacement of a beam made of $\mathrm{Al} / \mathrm{Al}_{2} \mathrm{O}_{3}$ functionally graded materials, subjected to a uniformly distributed load, for different values of the power-law index $\mathrm{p}$ which takes the values $0,1,2,5$ and 10 with a ratio of $(\mathrm{L} / \mathrm{h}=5)$. It can be seen through these curves that the axial displacement is influenced by the index of the 
power-law $\mathrm{p}$ since the dimensionless displacement increases as the index of the power-law increases and precisely in the two upper and lower parts of the beam.

\begin{tabular}{|c|c|c|c|c|c|c|c|c|c|}
\hline \multirow[b]{2}{*}{$p$} & \multirow[b]{2}{*}{ Theory } & \multicolumn{4}{|c|}{$\mathrm{L} / \mathrm{h}=5$} & \multicolumn{4}{|c|}{$\mathrm{L} / \mathrm{h}=20$} \\
\hline & & $\bar{u}$ & $\bar{w}$ & $\bar{\sigma}_{x}$ & $\bar{\tau}_{x z}$ & $\bar{u}$ & $\bar{w}$ & $\bar{\sigma}_{x}$ & $\bar{\tau}_{x z}$ \\
\hline \multirow{6}{*}{$\mathbf{0}$} & Present $\left(\varepsilon_{z} \neq 0\right)$ & 0.8569 & 2.9063 & 3.8071 & 0.7325 & 0.2098 & 2.6372 & 15.0143 & 0.7455 \\
\hline & Present $\left(\varepsilon_{z}=0\right)$ & 0.9397 & 3.1654 & 3.8019 & 0.7332 & 0.2306 & 2.8962 & 15.0129 & 0.7437 \\
\hline & Hadji et al. [25] & 0.9400 & 3.1654 & 3.8019 & 0.7330 & 0.2305 & 2.8962 & 15.0129 & 0.7437 \\
\hline & A.S. Sayyad and Y.M.Ghugal [58] & 0.9274 & 3.1224 & 3.7529 & 0.7259 & 0.2275 & 2.8585 & 14.8179 & 0.7259 \\
\hline & Reddy [11] & 0.9397 & 3.1654 & 3.8019 & 0.7330 & 0.2306 & 2.8962 & 15.0129 & 0.7437 \\
\hline & Present $\left(\varepsilon_{z} \neq 0\right)$ & 2.0993 & 5.7397 & 5.8924 & 0.7325 & 0.5174 & 5.2852 & 23.2076 & 0.7455 \\
\hline \multirow[t]{5}{*}{1} & Present $\left(\varepsilon_{z}=0\right)$ & 2.3038 & 6.2594 & 5.8835 & 0.7330 & 0.5685 & 5.8049 & 23.2051 & 0.7437 \\
\hline & Hadji et al. [25] & 2.3038 & 6.2594 & 5.8835 & 0.7330 & 0.5685 & 5.8049 & 23.2051 & 0.7437 \\
\hline & A.S. Sayyad and Y.M.Ghugal [58] & 2.2735 & 6.2586 & 5.8077 & 0.7187 & 0.5611 & 5.7292 & 22.9038 & 0.7259 \\
\hline & Reddy [11] & 2.3036 & 6.2594 & 5.8836 & 0.7330 & 0.5686 & 5.5685 & 23.2051 & 0.7432 \\
\hline & Present $\left(\varepsilon_{z} \neq 0\right)$ & 2.8363 & 7.4016 & 6.8940 & 0.6699 & 0.6999 & 6.7760 & 27.1021 & 0.6828 \\
\hline \multirow[t]{5}{*}{2} & Present $\left(\varepsilon_{z}=0\right)$ & 3.1129 & 8.0677 & 6.8824 & 0.6704 & 0.7366 & 7.2558 & 27.0989 & 0.6812 \\
\hline & Hadji et al. [25] & 3.1129 & 8.0677 & 6.8824 & 0.6704 & 0.7366 & 7.2558 & 27.0989 & 0.6812 \\
\hline & A.S. Sayyad and Y.M.Ghugal [58] & 3.0720 & 7.9627 & 6.7938 & 0.6573 & 0.7591 & 7.3450 & 26.7470 & 0.6648 \\
\hline & Reddy [11] & 3.1127 & 8.0677 & 6.8824 & 0.6704 & 0.7691 & 7.4421 & 27.0989 & 0.6812 \\
\hline & Present $\left(\varepsilon_{z} \neq 0\right)$ & 3.3815 & 9.0403 & 8.1272 & 0.5898 & 0.8313 & 8.0 .06 & 31.8173 & 0.6025 \\
\hline \multirow[t]{5}{*}{5} & Present $\left(\varepsilon_{z}=0\right)$ & 3.7100 & 9.8281 & 8.1104 & 0.5904 & 0.9134 & 8.8182 & 32.8127 & 0.6013 \\
\hline & Hadji et al. [25] & 3.7100 & 9.8281 & 8.1104 & 0.5904 & 0.9134 & 8.8182 & 32.8127 & 0.6013 \\
\hline & A.S. Sayyad and Y.M.Ghugal [58] & 3.6612 & 9.6986 & 8.0059 & 0.5786 & 0.9014 & 8.7031 & 31.3997 & 0.5863 \\
\hline & Reddy [11] & 3.7097 & 9.8281 & 8.1104 & 0.5904 & 0.9134 & 8.8182 & 31.8127 & 0.6013 \\
\hline & Present $\left(\varepsilon_{z} \neq 0\right)$ & 3.5434 & 10.0733 & 9.7310 & 0.6459 & 0.8679 & 8.8259 & 38.1434 & 0.6599 \\
\hline \multirow[t]{4}{*}{10} & Present $\left(\varepsilon_{z}=0\right)$ & 3.7462 & 10.9381 & 9.7123 & 0.6467 & 0.9536 & 9.6905 & 38.1387 & 0.6600 \\
\hline & Hadji et al. [25] & 3.8863 & 10.9381 & 9.9878 & 0.7064 & 0.9262 & 9.5513 & 38.1382 & 0.6586 \\
\hline & A.S. Sayyad and Y.M.Ghugal [58] & 3.8351 & 10.7949 & 9.5870 & 0.6412 & 0.9412 & 9.5641 & 37.6432 & 0.6426 \\
\hline & Reddy [11] & 3.8859 & 10.9381 & 9.7119 & 0.6465 & 0.9536 & 9.6905 & 38.1382 & 0.6586 \\
\hline
\end{tabular}

Table 2: Comparison of the dimensionless displacements and stress of the FG beams subjected to uniformly distributed load with various power-law exponent values.

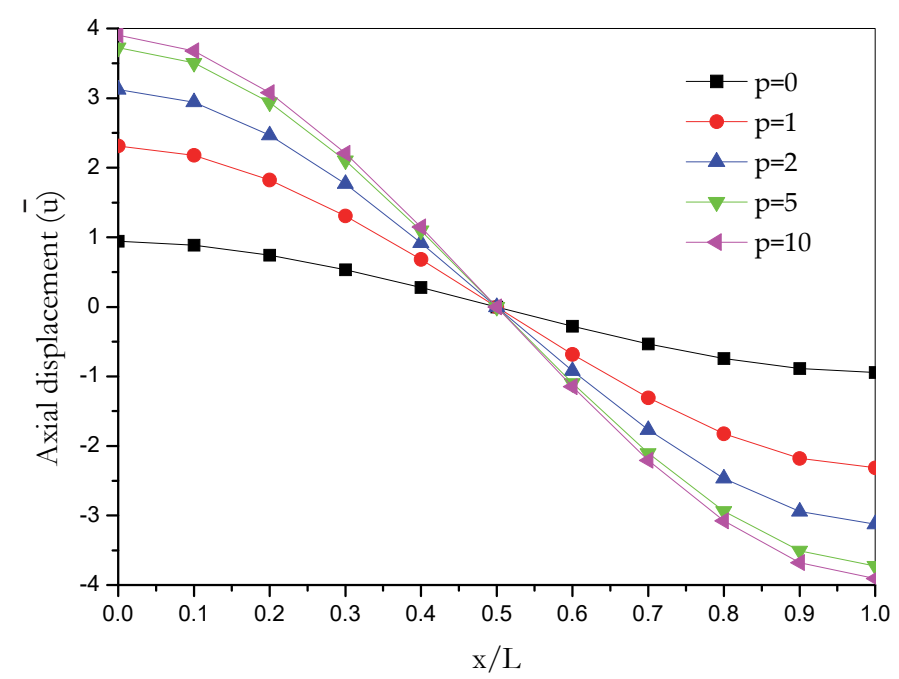

Figure 5: Variation of dimensionless axial displacement $(\overline{\mathrm{u}})$ along the length of the beam subjected to uniformly distributed load with a ratio $(\mathrm{L} / \mathrm{h}=5)$. 


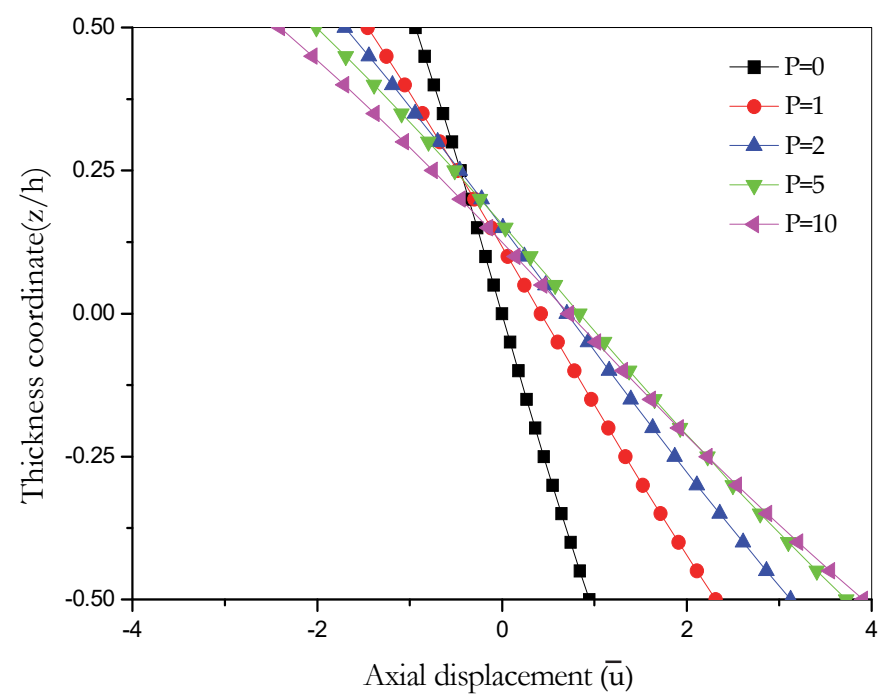

Figure 6: Variation of the dimensionless axial displacement $(\overline{\mathrm{u}})$ across the thickness of an FG beam subjected to uniformly distributed load with a ratio $(\mathrm{L} / \mathrm{h}=5)$.

The Fig. 7 illustrates the variation of the axial stress of a beam made of $\mathrm{Al} / \mathrm{Al}_{2} \mathrm{O}_{3}$ functionally graded materials, subjected to a uniformly distributed load, for different values of the index of the power-law $\mathrm{p}$ which takes the values $0,1,2,5$ and 10 with a ratio of $(\mathrm{L} / \mathrm{h}=5)$. It can be deduced that the upper part is towed and the lower part is compressed and between these two parts the curve takes a parabolic form.

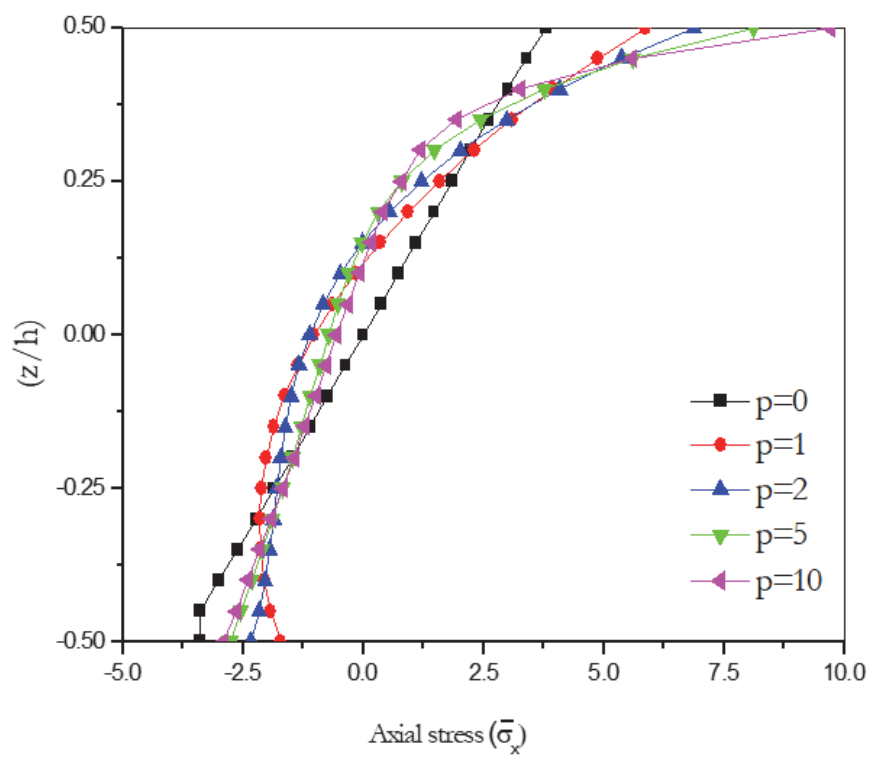

Figure 7: Variation of the dimensionless axial stress across the thickness of the FG beam subjected to uniformly distributed load with a ratio $(\mathrm{L} / \mathrm{h}=5)$.

The Fig. 8 shows the variation of the transverse shear stress of a beam in $\mathrm{Al} / \mathrm{Al}_{2} \mathrm{O}_{3}$ functionally graded materials, subjected to a uniformly distributed load for different values of the index of the power-law $\mathrm{p}$ which takes the values of 0 , $1,2,5$ and 10 with a ratio of $(\mathrm{L} / \mathrm{h}=5)$. It is observed that the plot of the transverse shear stress does not take a parabolic form as in the case of homogeneous beams of metal and ceramic, it can also be noted that the neutral axis is eccentric towards the upper part. 


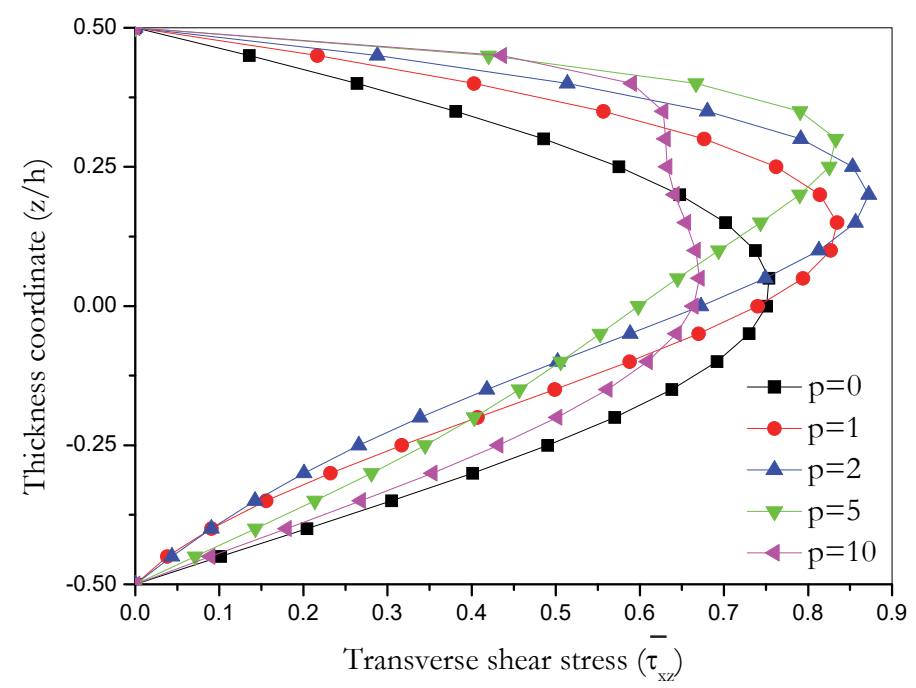

Figure 8: Variation of the dimensionless transverse shear stress through the thickness of the FG beam subjected to uniformly distributed load with a ratio $(\mathrm{L} / \mathrm{h}=5)$.

\section{BUCKLING ANALYSIS}

$\mathrm{n}$ this part we have studied the comparison of dimensionless critical buckling loads $(\overline{\mathrm{N}} c r)$ for $\mathrm{Al} / \mathrm{Al}_{2} \mathrm{O}_{3}$ type functionally graded beams, simply supported and subjected to axial forces $\left(\mathrm{N}_{0}\right)$ with respect to different values of the exponent of the law of power $\mathrm{p}$ for the ratios $\mathrm{L} / \mathrm{h}=5$ and 10 . It is observed that the critical load of dimensionless buckling decreases with the growth of the index of the law of power $\mathrm{p}$ and it increases with the increase of the ratio $(\mathrm{L} / \mathrm{h})$. The results of the critical buckling load obtained in Tab. 3 are compared with other results of the literature such as HSDT of Reddy [11], FSDT of Touratier [12], HSDT of A.S. Sayyad and Y.M. Ghugal [58], FSDT of Li and Batra [23], and HSDT of Vo et al. [30]. It can also be noted that the theory of two-dimensional shear deformation (2D) is in good agreement with the other theories of shear deformation, whereas the results obtained by the theory of quasi-threedimensional shear deformation (quasi-3D) are slightly larger than those of the literature and this is due to the effect of the normal transversal deformation which is not neglected $\left(\varepsilon_{z} \neq 0\right)$ compared to other theories where the effect of the normal transverse deformation is neglected $\left(\varepsilon_{z}=0\right)$.

\begin{tabular}{clccccc}
\hline \multicolumn{1}{c}{ Theory } & & & $\boldsymbol{p}$ & & \\
& & 0 & 1 & 2 & 5 & 10 \\
& & 52.916 & 26.805 & 20.783 & 17.002 & 15.253 \\
& Present $\left(\varepsilon_{z} \neq 0\right)$ & 48.596 & 24.584 & 19.071 & 15.645 & 14.052 \\
& Present $\left(\varepsilon_{z}=0\right)$ & 48.596 & 24.584 & 19.071 & 15.645 & 14.052 \\
& A.S. Sayyad and Y.M. Ghugal [58] & 48.596 & 24.584 & 19.071 & 15.643 & 14.051 \\
$\mathbf{5}$ & 48.835 & 24.687 & 19.245 & 16.024 & 14.427 \\
& Reddy [11] & 48.835 & 24.687 & 19.245 & 16.024 & 14.427 \\
& Touratier [12] & 48.840 & 24.691 & 19.160 & 16.740 & 14.146 \\
& Li and Batra [23] & 57.262 & 28.666 & 22.330 & 18.714 & 16.974 \\
& Vo et al. [30] & 52.238 & 26.141 & 20.366 & 17.082 & 15.500 \\
& Present $\left(\varepsilon_{z} \neq 0\right)$ & 52.238 & 26.141 & 20.366 & 17.082 & 15.500 \\
& Present $\left(\varepsilon_{z}=0\right)$ & 52.238 & 26.141 & 20.366 & 17.082 & 15.499 \\
& A.S. Sayyad and Y.M. Ghugal [58] & 52.309 & 26.171 & 20.416 & 17.192 & 15.612 \\
$\mathbf{1 0}$ & Reddy [11] & 52.309 & 26.171 & 20.416 & 17.194 & 15.612 \\
& Touratier [12] & 52.308 & 26.172 & 20.393 & 17.111 & 15.529 \\
\hline
\end{tabular}

Table 3: Comparison of the dimensionless critical buckling loads $(\bar{N} c r)$ of the FG beams subjected to axial forces in regards to various power-law exponent values. 


\section{VIBRATION ANALYSIS}

[ $\mathrm{n}$ this third part of our work, we studied the first three fundamental dimensionless frequencies of $\mathrm{Al} / \mathrm{Al}_{2} \mathrm{O}_{3}$ type functionally graded materials beams for various exponent values of the power-law $\mathrm{p}$ and the ratio $(\mathrm{L} / \mathrm{h})$.

\begin{tabular}{|c|c|c|c|c|c|c|c|}
\hline \multirow[t]{2}{*}{$\mathrm{L} / \mathrm{h}$} & \multirow[t]{2}{*}{ Mode } & \multirow[t]{2}{*}{ Theory } & \multicolumn{5}{|c|}{$p$} \\
\hline & & & 0 & 1 & 2 & 5 & 10 \\
\hline \multirow{23}{*}{5} & \multirow{9}{*}{1} & Present $\left(\varepsilon_{z} \neq 0\right)$ & 5.3781 & 4.1677 & 3.7867 & 3.5470 & 3.4203 \\
\hline & & Present $\left(\varepsilon_{z}=0\right)$ & 5.1527 & 3.9904 & 3.6264 & 3.4014 & 3.2816 \\
\hline & & A.S. Sayyad and Y.M.Ghugal [58] & 5.1527 & 3.9904 & 3.6264 & 3.4014 & 3.2816 \\
\hline & & Reddy [11] & 5.1527 & 3.9904 & 3.6264 & 3.4012 & 3.2816 \\
\hline & & Touratier [12] & 5.1531 & 3.9906 & 3.6263 & 3.3997 & 3.2811 \\
\hline & & Simsek [15] & 5.1527 & 3.9904 & 3.6264 & 3.4012 & 3.2816 \\
\hline & & Thai and Vo [20] & 5.1527 & 3.9904 & 3.6264 & 3.4012 & 3.2816 \\
\hline & & Vo et al. [29] & 5.1526 & 3.9711 & 3.6050 & 3.4012 & 3.2962 \\
\hline & & Vo et al. [30] & 5.1527 & 3.9716 & 3.5979 & 3.3742 & 3.2653 \\
\hline & \multirow{10}{*}{2} & Timoshenko [10] & 5.1524 & 3.9902 & 3.6343 & 3.4311 & 3.3134 \\
\hline & & Bernoulli-Euler [9] & 5.3953 & 4.1484 & 3.7793 & 3.5949 & 3.4921 \\
\hline & & Present $\left(\varepsilon_{z} \neq 0\right)$ & 17.514 & 14.531 & 13.105 & 11.932 & 11.380 \\
\hline & & Present $\left(\varepsilon_{z}=0\right)$ & 17.881 & 14.010 & 12.640 & 11.544 & 11.024 \\
\hline & & A.S. Sayyad and Y.M.Ghugal [58] & 17.881 & 14.010 & 12.640 & 11.544 & 11.024 \\
\hline & & Reddy [11] & 17.881 & 14.010 & 12.640 & 11.543 & 11.025 \\
\hline & & Touratier [12] & 17.887 & 14.014 & 12.641 & 11.532 & 11.021 \\
\hline & & Thai and Vo [20] & 17.881 & 14.009 & 12.640 & 11.544 & 11.024 \\
\hline & & Bernoulli-Euler [9] & 20.618 & 15.798 & 14.326 & 13.587 & 13.237 \\
\hline & & Present $\left(\varepsilon_{z} \neq 0\right)$ & 35.173 & 27.930 & 25.052 & 22.289 & 21.061 \\
\hline & \multirow{4}{*}{3} & Present $\left(\varepsilon_{z}=0\right)$ & 34.209 & 27.098 & 24.316 & 21.720 & 20.556 \\
\hline & & A.S. Sayyad and Y.M.Ghugal [58] & 34.202 & 27.098 & 24.316 & 21.720 & 20.556 \\
\hline & & Reddy [11] & 34.209 & 27.098 & 24.315 & 21.716 & 20.556 \\
\hline & & Touratier [12] & 34.234 & 27.115 & 24.324 & 21.694 & 20.558 \\
\hline \multirow{27}{*}{20} & \multirow{13}{*}{1} & Thai and Vo [20] & 34.208 & 27.097 & 24.315 & 21.718 & 20.556 \\
\hline & & Bernoulli-Euler [9] & 43.348 & 33.027 & 29.745 & 28.085 & 27.475 \\
\hline & & Present $\left(\varepsilon_{\mathrm{z}} \neq 0\right)$ & 5.7222 & 4.4069 & 4.0202 & 3.8232 & 3.7083 \\
\hline & & Present $\left(\varepsilon_{z}=0\right)$ & 5.4603 & 4.2050 & 3.8361 & 3.6485 & 3.5389 \\
\hline & & A.S. Sayyad and Y.M.Ghugal [58] & 5.4603 & 4.2050 & 3.8361 & 3.6485 & 3.5390 \\
\hline & & Reddy [11] & 5.4603 & 4.2050 & 3.8361 & 3.6485 & 3.5389 \\
\hline & & Touratier [12] & 5.4603 & 4.2051 & 3.8361 & 3.6484 & 3.5389 \\
\hline & & Simsek [15] & 5.4603 & 4.2050 & 3.8361 & 3.6485 & 3.5389 \\
\hline & & Thai and Vo [20] & 5.4603 & 4.2050 & 3.8361 & 3.6484 & 3.5389 \\
\hline & & Vo et al. [29] & 5.4603 & 4.2038 & 3.8349 & 3.6490 & 3.5405 \\
\hline & & Vo et al. $[30]$ & 5.4603 & 4.2038 & 3.8342 & 3.6466 & 3.5378 \\
\hline & & Timoshenko [10] & 5.4603 & 4.2050 & 3.8367 & 3.6508 & 3.5415 \\
\hline & & Bernoulli-Euler [9] & 5.4777 & 4.2163 & 3.8472 & 3.6628 & 3.5547 \\
\hline & \multirow{7}{*}{2} & Present $\left(\varepsilon_{z} \neq 0\right)$ & 22.587 & 17.420 & 15.877 & 15.046 & 14.574 \\
\hline & & Present $\left(\varepsilon_{\mathrm{z}}=0\right)$ & 21.573 & 16.643 & 15.161 & 14.374 & 13.926 \\
\hline & & A.S. Sayyad and Y.M.Ghugal [58] & 21.573 & 16.643 & 15.161 & 14.374 & 13.926 \\
\hline & & Reddy [11] & 21.573 & 16.634 & 15.162 & 14.374 & 13.926 \\
\hline & & Touratier [12] & 21.574 & 16.635 & 15.162 & 14.373 & 13.925 \\
\hline & & Thai and Vo [20] & 21.573 & 16.643 & 15.161 & 14.374 & 13.926 \\
\hline & & Bernoulli-Euler [9] & 21.843 & 16.810 & 15.333 & 14.595 & 14.167 \\
\hline & \multirow{7}{*}{3} & Present $\left(\varepsilon_{z} \neq 0\right)$ & 49.761 & 38.458 & 35.003 & 32.998 & 31.899 \\
\hline & & Present $\left(\varepsilon_{\mathrm{z}}=0\right)$ & 47.593 & 36.768 & 33.469 & 31.579 & 30.095 \\
\hline & & A.S. Sayyad and Y.M.Ghugal [58] & 47.593 & 36.768 & 33.469 & 31.579 & 30.095 \\
\hline & & Reddy [11] & 47.593 & 36.768 & 33.469 & 31.578 & 30.537 \\
\hline & & Touratier [12] & 47.595 & 36.769 & 33.468 & 31.570 & 30.534 \\
\hline & & Thai and $V_{0}[20]$ & 47.593 & 36.767 & 33.469 & 31.5789 & 30.537 \\
\hline & & Bernoulli-Euler [9] & 48.899 & 37.617 & 34.295 & 32.6357 & 31.688 \\
\hline
\end{tabular}

Table 4: Comparison of the first three dimensionless fundamental frequencies of the FG beams in regards to various power-law exponent values. 
Observe that the fundamental non-dimensional frequencies for the first three modes decrease with the growth of the power-law index and they increase with the increase of the ratio $(\mathrm{L} / \mathrm{h})$, this is because of an increase in the power-law index $\mathrm{p}$ makes the beam more flexible. The results of the fundamental frequencies obtained in Tab. 4 are compared with other results such as HSDT of Reddy [11], HSDT of A.S. Sayyad and Y.M. Ghugal [58], FSDT of Touratier [12], HSDT of Simsek [15], HSDT of Thai and Vo [20], FSDT of Vo et al. [29], HSDT of Vo et al. [30], FSDT of Timoshenko [10], and CBT of Bernoulli-Euler [9]. It can also be noted that the two-dimensional shear deformation theory (2D) is in good agreement with that of the literature, whereas the results obtained by the theory of quasi-three-dimensional shear deformation (quasi-3D) are slightly larger compared to that of the literature and this is due to the effect of normal transversal deformation which is not neglected $\left(\varepsilon_{z} \neq 0\right)$ compared to other theories where the effect of normal transversal deformation is neglected $\left(\varepsilon_{\mathrm{z}}=0\right)$.

Fig. 9 illustrates the variation of the buckling critical load and the dimensionless fundamental natural frequency with respect to the index of the power-law $\mathrm{p}$ for different values of the ratio $(\mathrm{L} / \mathrm{h})$ by the use of the deformation theory shearing. It can be seen through these plots that the critical load and the frequency decreases with the growth of the index of the law of power $\mathrm{p}$, it is maximum when the law of power $\mathrm{p}$ takes the value of zero in this case, the beam is entirely ceramic and is minimal in the case where the index of the power-law p takes the value of one, in this case, the beam is entirely metal, this is due to the increase in the value of the index of the power-law which causes a decrease in the value of the modulus of elasticity. It can also be seen that the ratio $(\mathrm{L} / \mathrm{h})$ has a considerable effect on the critical buckling load and the fundamental dimensionless fundamental frequency when it is reduced, the value of the ratio (L/h) decreases. This dependence is related to the effect of shear deformation.

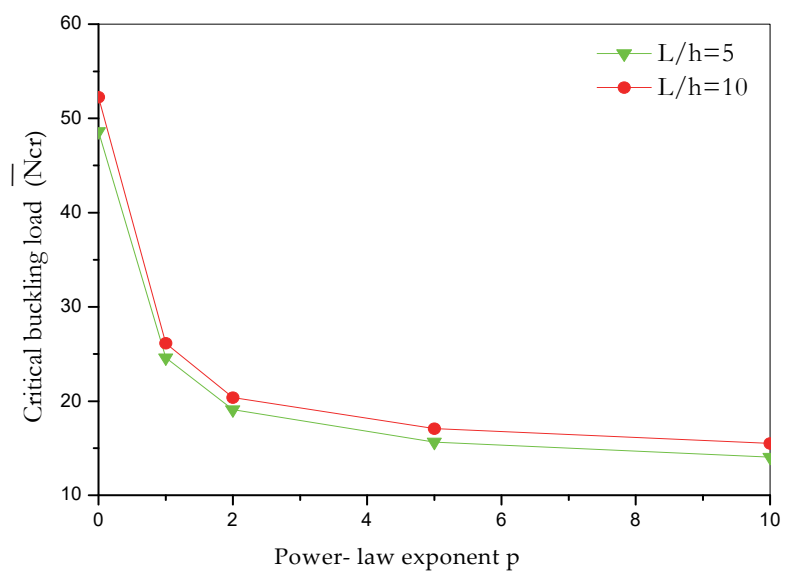

(a)

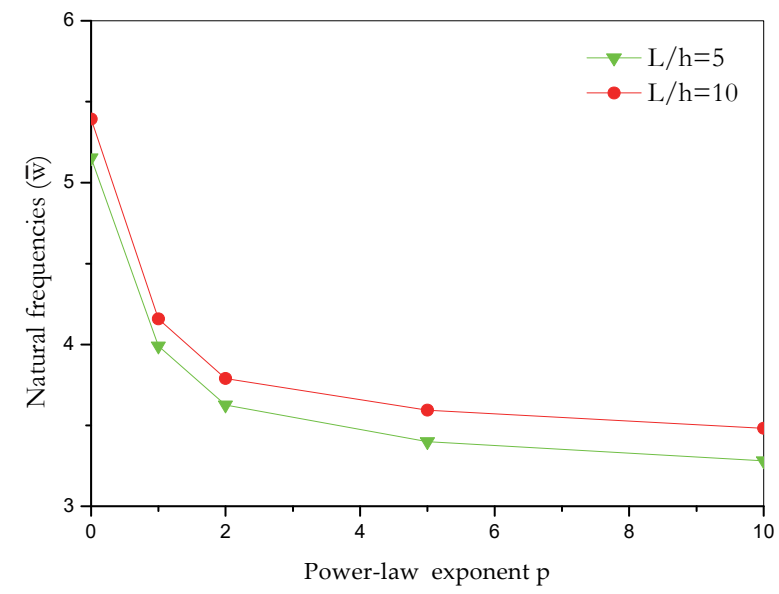

(b)

Figure 9: Variation in dimensionless critical buckling loads (a) and natural frequencies (b) with respect to the power-law exponents of exponents of simply supported FG beams.

\section{CONCLUSIONS}

he aim of our work is to study the bending, buckling, and vibration of beams functionally graded using a twodimensional (2D) and quasi-three-dimensional shear deformation theory (quasi-3D), without a need for introducing a shear correction factor. These beams are subjected to uniformly distributed loads. The principle of virtual works is used to solve equilibrium equations using the Navier approach with simply supported boundary conditions. The equations of motion are derived from the Hamilton principle. Parametric studies were carried out to examine the influence of the power-law index, and the beam aspect ratio $(\mathrm{L} / \mathrm{h})$ on the variation of dimensionless displacements as well as the distribution of dimensionless stresses across the thickness of a beam made of $\mathrm{Al} / \mathrm{Al}_{2} \mathrm{O}_{3}$ type functionally graded materials. The results obtained are in good agreement with the results of the literature. It can be said that the present theory of shear deformation with the taking into account the stretching effect is not only precise, but also provides an easily feasible approach for the simulation of the mechanical behavior of structures in order to design weak structures which can be used in several fields such as automotive, aeronautical, marine, medical and nuclear. In futuristic work, we envisage the study of these mechanical behaviors with other boundary conditions and different loadings that are mechanical or/and thermal. 


\section{REFERENCES}

[1] Niino, M., Hirai, T., Watanabe, R. (1987). The functionally gradient materials, J.Jpn. Soc. Compos. Mater. 13, 257264.

[2] Hashmi, S., Gilmar, F.B., Van Tyne, C.J., Yilbas, B.S. (2014). Comprehensive materials processing livre électronique, Oxford, Walltham, MA. Elsevier.

[3] Koizumi M. (1993). The concept of FGM. Ceramic Transactions, Functionally Gradient Materials. 34(1):3-10.

[4] Koizumi, M., Niino, M. (1995). Overview of FGM research in Japan. MRS Bull. 20, 19-24.

[5] Koizumi M. 1997. FGM activities in Japan. Composites Part B. 28, pp. 1-4.

[6] Karama, M., Afaq, K.S., Mistou, S. (2003). Mechanical behavior of laminated composite beam by the new multilayered laminated Composite Structures model with transverse shear stress continuity, Int. J. Solids Struct. 40(6), 1525-1546. DOI: 10.1016/S0020-7683(02)00647-9.

[7] Ayadoglu. M and Tashkin V. (2007). Free vibration analysis of functionally graded beams with simply supported edges. Materials and design. 28, 1681-1656. DOI: 10.1016/j.matdes.2006.02.007.

[8] Bernoulli, J. (1694). Curvatura laminate elasticae. Acte Eruditorum Lipsiae. 3(6), 262-276.

[9] Euler, L. (1744). Method usin venien diline ascurvas maximum inimive proprietate gaudentes.Lausanne and Geneva.

[10] Timoshenko, S. P. (1921). On the correction for shear of the differential equation for transverse vibrations of prismatic bars. Philosophical Magazine. 41, 742-746. DOI: 10.1080/14786442108636264.

[11] Reddy J.N. (1984). A simple higher order theory for laminated composite plates. J of Applied Mechanics. 51, pp. 745752. DOI: $10.1115 / 1.3167719$.

[12] Touratier M. (1991). An efficient standard plate theory. Int J Engineering Science. 29, pp. 901-916. DOI: 10.1016/0020-7225(91)90165-Y.

[13] Matsunaga, H., (2008). Free vibration and stability of functionally graded plates according to a 2-D higher-order deformation theory, Compos Struct. 82, pp. $499-512$.

[14] Vidal, P., Polit, O. (2009). Assessment of the refined sinus model for the non-linear analysis of composite beams, Compos. Struct. 87, pp. 370-381.

[15] Şimşek M. (2010). Fundamental frequency analysis of functionally graded beams by using different higher order beam theories, Nuclear Engineering and Design. 240(4), pp. 697.705. DOI: 10.1016/j.nucengdes.2009.12.013.

[16] Talha, M., Singh, B.N., (2010). Static response and free vibration analysis of FGM plates using higher-order shear deformation theory, Appl. Math. Model. 34(12), 3991-4011. DOI: 10.1016/j.apm.2010.03.034.

[17] Hosseini-Hashemi, S., Rokni Damavandi Taher, H., Akhavan, H., Omidi, M., (2010). Free vibration of functionally graded rectangular plates using first-order shear deformation plate theory, Appl. Math. Model. 34(5), pp. 1276-1291. DOI: $10.1016 /$ j.apm.2009.08.008.

[18] Hosseini-Hashemi, S., Fadaee, M., Atashipour, S.R., (2011a). A new exact analytical approach for free vibration of Reissner-Mindlin functionally graded rectangular plates, Int. J. Mech. Sci. 53(1), pp. 11-22. DOI: 10.1016/j.ijmecsci.2010.10.002.

[19] Xiang, S., Jin, Y.X., Bi, Z.Y., Jiang, S.X., Yang, M.S., (2011). A nth-order shear deformation theory for free vibration of functionally graded and composite sandwich plates, Compos. Struct. 93(11), pp. 2826-2832. DOI: $10.1007 / \mathrm{s} 11012-012-9563-0$.

[20] Thai, H. T., \& Vo, T. P. (2012). Bending and free vibration of functionally graded beams using various higher-order shear deformation beam theories. International Journal of Mechanical Sciences. 62, pp. 57-66.

DOI: 10.1016/j.ijmecsci.2012.05.014

[21] Reddy,J.N., (2011). Microstructure-dependent couple stress theories of functionally graded beams. Journal of the Mechanics and Physics of Solids. 59(11), pp. 2382-2399. DOI: 10.1016/j.jmps.2011.06.008

[22] Eltaher, M.A., Alshorbagy, A.E., Mahmoud, F.F., (2013). Determination of neutral axis position and its effect on natural frequencies of functionally graded macro/nano-beams, compos. Struct. 99, pp. 193-201.

[23] Li, S. R., \& Batra, R. C. 2013. Relations between buckling loads of functionally graded Timoshenko and homogeneous Euler- Bernoulli beams. Composite Structures. 95, pp. 5-9. DOI: 10.1016/j.compstruct.2012.07.027.

[24] Nguyen, T. K., Vo, T. P., \& Thai, H. T. (2013). Static and free vibration of axially loaded functionally graded beams based on the first-order shear deformation theory. Composites Part B Engineering. 55, pp. 147-157. DOI: 10.1016/j.compositesb.2013.06.01.

[25] Hadji, L., Daouadji, T. H., Meziane, M. A. A., Tlidji, Y., \& Bedia, E. A. A. (2016). Analysis of functionally graded beam using a new first-order shear deformation theory. Structural Engineering and Mechanics. 57, pp. 315-325. 
DOI: $10.12989 /$ sem.2016.57.2.315.

[26] Yaghoobi, H., Valipour, M.S., Fereidoon, A. and Khoshnevisrad, P., (2014). Analytical study on post-buckling and nonlinear free vibration analysis of FG beams resting on nonlinear elastic foundation under thermo-mechanical loading using VIM, Steel Compos. Struct. 17(5), pp. 753-776. DOI: 10.12989/scs.2014.17.5.753

[27] Rahmani, O. and Pedram, O. (2014). Analysis and modeling the size effect on vibration of functionally graded nanobeams based on nonlocal Timoshenko beam theory. International Journal of Engineering Science. 77, pp. 55-70. DOI: 10.1016/j.ijengsci.2013.12.003

[28] AlKhateeb et Zenkour. (2014). A refined four-unknown plate theory for advanced plates resting on elastic foundations in hygrothermal environment. Composite Structures. 111, pp. 240-248. DOI: 10.1016/j.compstruct.2013.12.033

[29] Vo, T. P., Thai, H. T., Nguyen, T. K., \& Inam, F. (2014a). Static and vibration analysis of functionally graded beams using refined shear deformation theory. Meccanica. 49, pp. 155-168.

[30] Vo, T. P., Thai, H. T., Nguyen, T. K., Maheri, A. and Lee, J. (2014b). Finite element model for vibration and buckling of functionally graded sandwich beams based on a refined shear deformation theory. Engineering Structures. 64, pp. 12-22. DOI: 10.1016/j.engstruct.2014.01.029.

[31] Meradjah, M., Kaci, A., Houari, M.S.A., Tounsi, A. and Mahmoud, S.R. (2015). A new higher order shear and normal deformation theory for functionally graded beams, Steel Compos. Struct. 18(3), pp. 793-809. DOI: $10.12989 /$ scs.2015.18.3.793.

[32] Vo, T. P., Thai, H. T., Nguyen, T. K., Inam, F., \& Lee, J. (2015). A quasi-3D theory for vibration and buckling of functionally graded sandwich beams. Composite Structures. 119, pp. 1-12. DOI: 10.1016/j.compstruct.2014.08.006.

[33] Zemri, A., Houari, M.S.A., Bousahla, A.A., Tounsi, A. (2015). A mechanical response of functionally graded nanoscale beam: an assessment of a refined nonlocal shears deformation theory beam theory, Structural Engineering and Mechanics. 54(4), pp. 693-710. DOI: 10.12989/sem.2015.54.4.693.

[34] Al-Basyouni, K.S., Tounsi, A. and Mahmoud, S.R. (2015). Size dependent bending and vibration analysis of functionally graded micro beams based on modified couple stress theory and neutral surface position, Compos. Struct. 125, pp. 621-630. DOI: 10.1016/j.compstruct.2014.12.070.

[35] Ebrahimi, F. and Dashti, S. (2015). Free vibration analysis of a rotating non-uniform functionally graded beam, Steel Compos.Struct.19(5), pp. 1279-1298. DOI: 10.12989/scs.2015.19.5.1279.

[36] Kar, V.R. and Panda, S.K. (2015). Nonlinear flexural vibration of shear deformable functionally graded spherical shell panel, Steel Compos. Struct., Int. J.18(3), pp. 693-709. DOI: 10.12989/scs.2015.18.3.693.

[37] Bourada M., Kaci A., Houari M.S.A., Tounsi A. (2015). A new simple shear and normal deformations theory for functionally graded beams, Steel and Composite Structures. 18(2), pp. 409-423. DOI: 10.12989/scs.2015.18.2.409.

[38] Celebi, K., Yarimpabuc, D., Keles, I. (2015). A unified method for stresses in FGM sphere with exponentially-varying properties, Struct. Eng. Mech. 57(5), pp. 823-835. DOI: 10.12989/sem.2016.57.5.823.

[39] Boukhari, A., Fouad, B., Djalil, B.A., Mohamed, B.B., Abdelouahed, T., Bedia, E.A. (2016). The thermal study of wave propagation in functionally graded material plates (FGM) based on neutral surface position, Mathematical Modelling of Engineering Problems. 3(4), pp. 202-205. DOI: 10.18280/mmep.030410.

[40] Ebrahimi and Barati. (2016a). A nonlocal higher-order shear deformation beam theory for vibration analysis of sizedependent functionally graded nanobeams. Arabian Journal for Science and Engineering. 41(5), pp. 1679-1690. DOI: $10.1007 /$ s13369-015-1930-4.

[41] Ahouel. M., Mohammed Sid Ahmed Houari, E.A. Adda Bedia and Abdelouahed Tounsi, (2016), Size-dependent mechanical behavior of functionally graded trigonometric shear deformable nano-beams including neutral surface position concept. Steel and Composite Structures. 20(5), pp. 963-981. DOI: 10.12989/scs.2016.20.5.963.

[42] Shafiei Navvab, Alireza Mousavi, Majid Ghadiri, (2016), On the size-dependent nonlinear vibration of porous and imperfect functionally graded tapered microbeams, International Journal of Engineering Science. 106, pp. 42-56. DOI: $10.1016 /$ j.ijengsci.2016.05.007

[43] Raminnea, M., Biglari, H. and Vakili Tahami, F. (2016). Nonlinear Dynamics Nonlinear higher order Reddy theory for temperature-dependent vibration and instability of embedded functionally graded pipes conveying fluid. Structural Engineering \& Mechanics. 59(1), pp. 153-186. DOI: 10.12989/sem.2016.59.1.153.

[44] Ghumare and Sayyad. (2017). Bending, buckling and free vibration of laminated composite and sandwich beams: A critical review of literature. Composite Structures. 171, pp. 486-504. DOI: 10.1016/j.compstruct.2017.03.053.

[45] Benadouda, M., Ait Atmane, H., Tounsi, A., Bernard, F., Mahmoud, S.R. (2017). An efficient shear deformation theory for wave propagation in functionally graded material beams with porosities, Earthquakes and Structures. 13(3), pp. 255-265. DOI: 10.12989/EAS.2017.13.3.255. 
[46] Bellifa, H., Benrahou, K.H., Hadji, L., Houari, M.S.A., Tounsi, A. (2016). Bending and free vibration analysis of functionally graded plates using a simple shear deformation theory and the concept the neutral surface position, $J$ Braz. Soc. Mech. Sci. Eng. 38, pp. 265-275. DOI: 10.1007/s40430-015-0354-0.

[47] Akbaş, S..D. (2015). Wave propagation of a functionally graded beam in thermal environments, Steel Compos. Struct. 19(6), pp. 1421-1447.

[48] Akbaş, Ş.D. (2016). Forced vibration responses of functionally graded viscoelastic beams under thermal environment, International Journal of Innovative Research in Science, Engineering and Technology. 5(12), pp. 36 - 46. DOI: 10.1142/S1758825117501009.

[49] Bellifa, H., Benrahou, K.H., Bousahla, A.A., Tounsi, A., Mahmoud, S.R. (2017b). A nonlocal zeroth-order shear deformation theory for nonlinear postbuckling of nanobeams, Structural Engineering and Mechanics. 62(6), pp. 695 702. DOI: 10.12989/SEM.2017.62.6.695.

[50] Li, L., Tang, H. and Hu, Y. (2018). The effect of thickness on the mechanics of nanobeams. International Journal of Engineering Science. 123, pp. 81-91. DOI: 10.1016/j.ijengsci.2017.11.021.

[51] Sayyad, A. S., \& Ghugal, Y. M. (2017b). A unified shear deformation theory for the bending of isotropic, functionally graded, laminated and sandwich beams and plates. International Journal of Applied Mechanics. 9(1), pp. 1-36. DOI: $10.1142 /$ S1758825117500077.

[52] Aldousari, S.M. (2017). Bending analysis of different material distributions of functionally graded beam, Appl. Phys. A. 123, pp. 296.

[53] Bouafia, K., Kaci, A., Houari, M. S. A., Benzair, A., Tounsi, A. (2017). A nonlocal quasi-3D theory for bending and free flexural vibration behaviors of functionally graded nanobeams, Smart Structures and Systems. 19(2), pp. 115-126. DOI: $10.12989 /$ sss.2017.19.2.115

[54]Zidi, M., Houari, M.S.A., Tounsi, A., Bessaim, A., Mahmoud, S.R. (2017). A novel simple two-unknown hyperbolic shear deformation theory for functionally graded beams, Struct. Eng.Mech. 64(2), pp. 145-153. DOI: $10.1016 /$ j.ast.2014.02.001.

[55] Fouda Noha, Tawfik El-midany, A. M. Sadoun, (2017), Bending, Buckling and Vibration of a Functionally Graded Porous Beam Using Finite Elements, Journal of applied and computational mechanics. 3, pp. $274-282$. DOI: 10.22055/JACM.2017.21924.1121.

[56]Zaoui F. Zohra, Hanifi H. A. Lemya, Younsi Abderahman, Meradjah Mustapha, Tounsi Abdelouahed, Ouinas Djamel, (2017). Free vibration analysis of functionally graded beams using a higher-order shear deformation theory, mathematical modelling of engineering problems. 1(1), pp.7-12. DOI: $10.18280 / \mathrm{mmep} .040102$.

[57] Mouffoki, A., Adda Bedia, E.A., Houari, M.S.A., Tounsi, A., Mahmoud, S.R. (2017). Vibration analysis of nonlocal advanced nanobeams in hygro-thermal environment using a new two-unknown trigonometric shear deformation beam theory, Smart Structures Systems. 20(3), pp. 369-383. DOI: 10.12989/sss.2017.20.3.369.

[58] Sayyad, A. S., \& Ghugal, Y. M. (2018). Bending, buckling and free vibration responses of hyperbolic shear deformation FGM beams. Mechanics of advanced composite structures. 5, pp. 13-24.

DOI: 10.22075/MACS.2018.12214.1117.

[59] Kaci, A., Houari, M.S.A., Bousahla, A.A., Tounsi, A., Mahmoud, S.R. (2018). Post-buckling analysis of sheardeformable composite beams using a novel simple two-unknown beam theory, Structural Engineering and Mechanics.65(5), pp. 621-631. DOI: 10.12989/sem.2018.65.5.621.

[60] Dragan Cukanovic, Aleksandar Radakovic', Gordana Bogdanovic', Milivoje Milanovic', Halit Redžovi'c and Danilo Dragovi'c. (2018). New Shape Function for the Bending Analysis of Functionally Graded Plate, Materials. 11, pp. 2381. DOI: $10.3390 / \mathrm{ma1} 1122381$.

[61] Bouremana, M, Houari, M.S.A., Tounsi, A.,Kaci, A. and Adda Bedia, E.A. (2013), A new first shear deformation beam theory based on neutral surface position for functionally graded beams, Steel Compos. Struct., 15(5), pp. 467479. DOI: $10.12989 / \mathrm{scs} .2013 .15 .5 .467$.

[62] Ould, L.L., Kaci, A., Houari, M.S.A. and Tounsi, A. (2013), An efficient shear deformation beamtheory based on neutral surface position for bending and free vibration of functionally graded beams, Mech.Bas.Des.Struct., 41(4), pp. 421-433. DOI: 10.1080/15397734.2013.763713.

[63] Şimşek, M.and Yurtcu, H.H. (2013), Analytical solutions for bending and buckling of functionally graded nanobeams based on the nonlocal Timoshenko beam theory, Compos. Struct., 97, pp. 378-386. DOI: $10.1016 /$ j.compstruct.2012.10.038

[64] Mantari JL, Granados EV. (2016). An original FSDT to study advanced composites on elastic foundation. ThinWalled Structures;107: 80e9. DOI: 10.1016/j.tws.2016.05.024.

[65] Reddy JN. (2002). Energy principles and variational methods in applied mechanics. John Wiley \& Sons Inc. 